\title{
"VERSANDO SENTIDOS" SOBRE O PROCESSO DE APRENDIZAGEM EM GESTALT-TERAPIA
}

\author{
"Traversing Meanings" About the Learning Process in Gestalt Therapy \\ "Ejercitando Sentidos “ Sobre el Proceso de Aprendizaje en Terapia Gestalt
}

JoÃo Vitor Moreira Maia

José CÉLIO Freire

Mariana Alves de Oliveira

\begin{abstract}
Resumo: Propomo-nos, a partir de um estudo exploratório, questionar: como se dá o processo de facilitação da aprendizagem em Gestalt-terapia no ambiente acadêmico? Fez-se necessário compreender como a Gestalt-terapia, em seus referenciais teóricos, entende o processo de facilitação da aprendizagem. Nesse sentido, nos detivemos em estudos sobre Gestaltpedagogia, e sobre a formação do psicoterapeuta na Abordagem Gestáltica. Ampliamos nossos referenciais a partir das ideias de Martin Buber sobre Educação e sobre a Filosofia Dialógica, estabelecendo também o diálogo com a Filosofia da Alteridade de Emmanuel Lévinas, especificamente no que diz respeito ao conceito de ensino. Partindo do pressuposto que tais referenciais teóricos orientam nossa prática docente, intencionamos ilustrar nosso entendimento e vivência sobre a temática utilizando-nos das versões de sentido realizadas por uma aluna que participou do Curso de Capacitação na Abordagem Gestáltica, oferecido aos estudantes de graduação do Curso de Psicologia na Universidade Federal do Ceará. Propomos uma prática docente que possibilite afetação, em que se experiencie o abandono das referências, das seguranças do conhecido, e que proponha um conhecimento a partir desta afetação provocada pela exposição ao outro do professor, dos livros e pelas experiências vividas a partir da experiência concreta em sala de aula.
\end{abstract}

Palavras-chave: Processo de aprendizagem; Gestalt-Terapia; Dialogicidade; Alteridade; Versão de sentido.

Abstract: Starting from an exploratory study, we are questioning How the process of learning facilitation in Gestalt therapy works in the academic environment? It was necessary to understand how Gestalt Therapy views the process of learning facilitation in its theoretical references. Accordingly, we focus our readings in the Gestaltpedagogy studies, and on the training of psychotherapists in the Gestalt approach. We expanded our references from the ideas of Martin Buber on Education and Dialogical Philosophy as well, thus establishing a dialogue with Emmanuel Levinas's Otherness Philosophy, specifically regarding the concept of Teaching. Assuming that such theoretical references guide our teaching practice, we intend to illustrate our understanding and experience on the subject using the versions of meanings performed by a student who participated in the Training Course in the Gestalt Approach, offered to Psychology Course graduating students at the Federal University Federal of Ceará. We propose a teaching practice that enables affectation, the experiences of references` abandonment, the security of the known. We are proposing a knowledge from this affectation caused by exposure to the otherness of the teacher, of the books and the experiences from the concrete experience in the classroom.

Keywords: Learning process; Gestalt Therapy; Dialogicality; Otherness; Versions of meanings.

Resumen: Se propone como un estudio exploratorio interrogar: ¿cómo es el proceso de facilitar el aprendizaje en la terapia Gestalt en el ámbito académico? Se hizo necesario entender cómo la terapia Gestalt en sus referencias teóricas entiende el proceso de facilitar el aprendizaje. Con ello, nos detuvimos en estudios sobre Gestaltpedagogía, y sobre la formación del psicoterapeuta el Abordaje Gestáltica. Hemos ampliado nuestras referencias a partir de las ideas de Martin Buber sobre Educación y sobre Filosofía Dialógica, estableciendo asimismo el diálogo con la Filosofía de la Alteridad de Emmanuel Levinas, en particular con respecto al concepto de la enseñanza. Suponiendo que tales referenciales teóricos orientan nuestra práctica docente, tenemos la intención de ilustrar nuestro conocimiento y la experiencia sobre el tema utilizándonos de las versiones de sentido realizadas por una estudiante que participó del Curso de Capacitación en el enfoque de la Gestalt, que se ofrece a los estudiantes del Curso de Psicología de la Universidad Federal de Ceará. Proponemos una práctica docente que permite la afectación, como lo experimenta el abandono de los referenciales, la seguridad del conocido, y proponer un conocimiento desde esta afectación causada por la exposición al otro del profesor, de los libros y de las experiencias vividas en la experiencia concreta en las clases.

Palabras-clave: Proceso de aprendizaje; La terapia gestalt; Dialogicidad; Alteridad; Versión de sentidos. 


\section{Introdução}

Este trabalho tem por objetivo apresentar os relatos iniciais das experiências vividas e as reflexões construídas a partir do Curso de Capacitação na Abordagem Gestáltica, oferecido aos alunos de graduação do Curso de Psicologia da Universidade Federal do Ceará, em Fortaleza, como projeto específico do PROPAG/UFC, no qual propomos uma atividade essencialmente relacionada ao processo de ensino/aprendizagem da Gestalt-terapia como abordagem psicológica e atuação clínica. Buscou-se ao longo do curso proporcionar uma melhor fundamentação epistemológica e teórica, colaborando com a formação do psicoterapeuta iniciante, no sentido também de proporcionar um maior embasamento teórico-vivencial na Abordagem Gestáltica.

Ao longo do curso referido, intencionamos examinar as temáticas relativas às bases históricas e epistemológicas da Gestalt-terapia, em sua implicação na teoria e nos fundamentos da prática clínica nesta abordagem. Destaca-se que, por compreender as psicologias como construções sócio-históricas, propomos uma reflexão crítica acerca dos conhecimentos e práticas produzidas pelas Psicologias, e mais especificamente pela Gestaltterapia, buscando entender as circunstâncias históricas, sociais, econômicas e políticas em que as abordagens psicológicas foram construídas e legitimadas socialmente, sabendo que este processo de construção persiste e se renova constantemente.

Observamos que, na condição de abordagem psicológica, a Gestalt-terapia vem, em sua história recente, se aproximando do espaço acadêmico, com gestalt-terapeutas ocupando cada vez mais o lugar na docência e na elaboração de trabalhos acadêmicos - trabalhos de conclusão de curso, dissertações de mestrado e teses de doutoramento - que trazem como temáticas questões teóricas e práticas relacionadas à Abordagem Gestáltica. Contudo, ainda nos parecem escassos os trabalhos que se propõem a versar sobre o processo de ensino/aprendizagem na Gestalt-terapia no âmbito acadêmico, que em nosso entendimento traz desafios diferentes dos normalmente encontrados nos cursos de formação/especialização nesta abordagem. Intencionamos, ao longo do presente trabalho, apresentar e discutir os desafios encontrados em nossa experiência, fazendo também provocações sobre a pertinência desta temática e a necessidade de estudos que venham a alargar tais questionamentos, entendendo que os temas aqui refletidos necessitam de um esforço mais árduo do que o espaço de um artigo nos possibilita.

Destacamos a importância de discutirmos o processo de aprendizagem da Gestalt-terapia no campo acadêmico, também pela forma que historicamente as abordagens humanistas são apresentadas e discutidas nos cursos de graduação. Neste sentido, Moreira (2007) nos fala que as abordagens psicológicas humanistas, muitas vezes a partir da preocupação prioritária com a experiência, teriam colocado a teorização em segundo plano, o que viria a possibilitar a concepção de que "a formação do psicoterapeuta humanista é mais fácil e que o aluno teria que estudar menos, uma vez que o que vale é a vivência das emoções" (p. 97). Moreira (2007) ressalta a necessidade da fundamentação teórico-filosófica dos enfoques psicoterápicos humanistas, enfatizando a importância da pesquisa fenomenológica mundana, na elaboração de uma "prática clínica competente, comprometida com o homem e com o mundo" (p. 108).

Ao analisarmos a história da Gestalt-terapia como abordagem psicoterápica, nos deparamos com o fato de que ela “(...) esteve tradicionalmente avessa à teorização e aos 'sobreísmos', intencionando com isso jamais desprender-se da realidade última e insuperável que é a vivência” (Karwowski, 2005, pp. 9-10). Tal compreensão gerou um distanciamento de seus teóricos, em suas primeiras décadas de história, do desafio e disciplina na construção de uma fundamentação teórico-epistemológica consistente e coerente, ressaltando que, desde a década de oitenta, percebe-se um esforço por parte dos maiores expoentes da comunidade gestáltica na construção desse alicerce teórico.

Neste sentido, Holanda (2005) ressalta que "a teoria e a prática de uma abordagem não podem estar dissociadas de uma construção coerente e de uma fundamentação sólida, bem como devem estar situadas num determinado contexto" (p. 24). Assim, tomamos como compromisso em nossa prática docente o ensino da Gestalt-terapia pautado em um rigor teórico-epistemológico, no entanto, sem esquecermos do aspecto vivencial, tão enfatizado pelas abordagens fenomenológico-existenciais.

Na medida em que as abordagens psicológicas, "devem estar situadas num determinado contexto", como aponta Holanda (2005, p. 24), tomamos também como desafio as colocações de Figueiredo (2009), quando afirma sobre a urgência em estabelecermos em nossas teorizações “(...) uma discussão histórica, sociológica e filosófica acerca do mundo em que vivemos, das formas dominantes de existir neste mundo e de como as psicologias contemporâneas são modos de tomar partido em relação aos problemas da contemporaneidade" (p. 30).

Assim, a partir desta proposta de atividade docente e das experiências vivenciadas ao longo do processo, surgiu a necessidade de questionar: como se dá o processo de facilitação da aprendizagem em Gestalt-terapia no ambiente acadêmico? Na tentativa de responder esta interrogação, primeiramente, fez-se necessário compreender como a Gestalt-terapia em seus referenciais teóricos entende o processo de ensino/aprendizagem. Neste sentido, recorremos aos trabalhos de Burow e Scherpp (1985) sobre a Gestaltpedagogia, e de Cardella (2002) sobre a formação do psicoterapeuta. Ampliamos nossos referenciais para os trabalhos de Martin Buber sobre Educação e sobre a filosofia dialógica, e propomo-nos também o diálogo com a filosofia da alteridade radical de Emmanuel Lévinas. 


\section{A Influência da Gestaltpedagogia}

Burow e Scherpp (1985) entendem a Gestaltpedagogia como um termo abrangente para conceitos pedagógicos que se orientam pelas ideias teóricas e práticas da Gestaltterapia e da Psicologia da Gestalt. Ressaltam que antes que se inicie qualquer prática pedagógica faz-se necessário que se tenham claros os objetivos, antes mesmo que se busquem os métodos e conteúdos com os quais eles possam ser melhor alcançados. Toma-se também como premissa que os objetivos, os meios e conteúdos de ensino se encontram em dependência recíproca, afirmando-se assim, a necessidade de harmonizá-los.

Burow e Scherpp (1985) ao retratar o trabalho de Besems, um gestaltpedagogo que formula explicitamente seus objetivos a partir de uma perspectiva político-social - em sua concepção de um ensino intersubjetivo - citam quatro objetivos amplos:

(1) A autoconscientização e a ampliação das próprias possibilidades, dos modelos de comunicação e do comportamento frente aos outros e às coisas, e das possibilidades de mudança direta do meio social [...] (2) Proporcionar discernimento sobre o próprio funcionamento e sobre as relações históricas e sociais desse funcionamento nos contextos interpessoal e social [...] (3) A ampliação das possibilidades de escolha do indivíduo quanto a si próprio, quanto aos outros e em relação ao mundo [...] (4) Criar premissas a fim de racionalizar o discernimento da interdependência de funções e, assim, possibilitar a representação ativa de interesses (pp. 109-110).

Podemos entender que, em uma prática orientada gestaltpedagogicamente, o objetivo central é o de possibilitar ao indivíduo o desenvolvimento de suas potencialidades e de uma consciência sócio-política. Para tanto, segundo a visão da gestaltpedagogia, é preciso apenas que se criem as condições necessárias.

Outro objetivo central da gestaltpedagogia é do levar em conta, de forma adequada, o aspecto emocional no processo de aprendizagem. Compreende-se que tomar o aspecto emocional também como um objetivo central é de fundamental importância para o processo de aprendizagem de uma abordagem psicológica, proposta em um espaço universitário, haja vista que, tradicionalmente, o ambiente acadêmico privilegia os conhecimentos cognitivos, em detrimento das outras formas de conhecimento.

Burow e Scherpp (1985) nos esclarecem que a modificação da relação interpessoal entre aluno e professor é de fundamental importância para a gestaltpedagogia. Pretende-se que o professor veja e aceite o aluno em sua existência como ser humano, como premissa para o desenvolvimento de um clima de confiança mútua, franqueza e autenticidade de comunicação na sala de aula. A relação intersubjetiva entre aluno e professor significa que este compreende e trata aquele como ser humano total, não sendo percebido somente em sua função de aluno.

Entende-se que na concretização da influência da gestaltpedagogia em práticas educacionais, dá-se ênfase aos aspectos experienciais dos afetos e emoções, de auto-conhecimento e das relações interpessoais da situação de aprendizagem. Sobre isso, parece-nos interessante e cabível estabelecermos um paralelo da proposta da gestaltpedagogia com algumas das críticas que Moreira (2007) tece à proposta educacional defendida por Carl Rogers.

Dentre outras críticas que Moreira (2007) formula sobre a abordagem centrada no aluno, proposta por Carl Rogers, destacamos uma que nos parece particularmente importante para revermos a influência da gestaltpedagogia nas práticas educacionais. Para Moreira (2007), Rogers na medida em que privilegia a experiência vivida pelo aluno enquanto pessoa desvaloriza a transmissão de conhecimentos no ensino, e nos adverte:

O ensino não somente inclui elementos que se relacionam com aspectos pessoais e sociais (objetivos da psicoterapia), mas também incorpora matérias mais específicas, relacionadas com a transmissão do saber. Uma sala de aula é o lugar onde se relacionam dialeticamente ser e saber, inseridos numa realidade institucional e, por conseguinte, social (p. 75).

Friedman (2002) quando nos fala sobre a perspectiva educacional em Martin Buber, refere-se a esta questão suscitada por Moreira (2007), apontando um conflito entre as perspectivas filosóficas modernas da educação, sugerindo que este segue até os dias atuais. De um lado, temos aqueles que enfatizam a importância de os objetivos educacionais serem obtidos a partir dos grandes livros, da tradição clássica, ou do conhecimento técnico. Do outro lado, estão aqueles que enfatizam o aspecto subjetivo do conhecimento e olham para a educação como o desenvolvimento do poder criativo ou como a assimilação das experiências pedagógicas a partir dos interesses e necessidades subjetivas do aluno. Friedman (2002) nos adverte que, dentro das reflexões de Buber sobre o processo educacional, estas duas propostas teóricas representam aspectos parciais de um todo, e afirma que a educação se dá quando:

(...) o aluno cresce através do encontro com a pessoa do professor e o Tu do escritor. Neste encontro, a realidade que o professor e o escritor lhe apresentam se torna viva para o aluno: ela é transformada de potencial, abstrata, e sem relação para uma forma atual, concreta, e como presença imediata da pessoa e ainda, em certo sentido, como uma relação de reciprocidade. Isso significa que, nenhuma verdadeira aprendizagem ocorre a menos que o aluno participe, mas também significa que o aluno deve encontrar algo realmente "outro" do que ele antes que possa aprender (p. 209). 
Tomamos como fundamento de nossa prática docente esta perspectiva, de que o processo educacional se dá pelo encontro do estudante com a pessoa do professor e com livro, na medida em que o aluno se vê implicado por este encontro com algo que lhe é diferente, outro. Temos aqui uma primeira sinalização do aprendizado pela alteridade, dos outros e dos livros, sem que possamos em nossas práticas de ensino prescindir dos aspectos pessoais e sociais, bem como dos objetivos mais específicos relacionados com a transmissão/ construção do saber.

\section{A Filosofia Dialógica de Martin Buber e suas Con- tribuições à Educação}

Outro referencial teórico que tomamos, e a partir do qual estabelecemos relações com o processo de ensino/ aprendizagem da Gestalt-terapia, é o pensamento filosófico de Martin Buber, a partir da antropologia filosófica. Dentre as contribuições de Buber para a reflexão sobre Educação, destacamos neste estudo as ideias de Inclusão e de Vereda Estreita, e suas reflexões sobre os modos como se dá o conhecimento, que nos possibilitam pensar o processo educacional menos pela via da construção metodológica, e mais por meio de uma perspectiva filosófica.

Por Inclusão, podemos entender a capacidade de o indivíduo, engajado no encontro dialógico, manter duplo sentimento, tendo consciência de si próprio e, ao mesmo tempo, percebendo o outro na sua alteridade singular. Para Buber (conforme citado por Hycner, 1997), a atitude de inclusão é fundamental para que se estabeleça uma relação dialógica genuína, traduzindo o conceito de inclusão como “(...) um salto audacioso - exigindo a mais intensa mobilização do próprio ser - na vida do outro" (p. 42).

Na perspectiva buberiana sobre educação, o mais importante no encontro do professor com o estudante é que ele experiencie o aluno do outro lado, sendo que se este processo é vivido de maneira real e concreta é removido o perigo de que o ensino se dê de maneira arbitrária, e se dê a partir do reconhecimento das necessidades dos alunos na relação destes com o mundo (Friedman, 2002). Outro conceito que pretendemos trabalhar neste estudo é o de Vereda Estreita. Por ele, Buber (1942/1963) desejava expressar que, como humanidade, não estamos situados sobre

(...) o amplo planalto de um sistema que compreende uma série de proposições seguras sobre o Absoluto, mas que me sustentava em uma vereda estreita que se erguía sobre o abismo, sem ter segurança alguma de um saber expressável em proposições, mas sim, tendo a certeza do encontro com o que permanece oculto (p. 126).
Essa metáfora, da Vereda Estreita, rejeita uma solução tranquila para as questões humanas, afirmando ainda a existência de paradoxos e contradições, presentes em cada situação da condição humana. Buber (1942/1963) formula esta perspectiva, se contrapondo às perspectivas filosóficas que buscam estabelecer uma condição de segurança a experiência humana, destacando dentre elas o pensamento hegeliano. Para Buber (1942/1963),

Hegel tenta dotar o homem com uma nova segurança (...) O sistema de Hegel representa, no pensamento ocidental, a terceira grande tentativa de segurança: depois da cosmologia de Aristóteles e a teologia de São Tomás, temos a logológica de Hegel. Ela subjuga qualquer insegurança, toda inquietude sobre o sentido, todo o medo pela decisão, toda problemática abissal (p. 48).

Buber (1942/1963) entende que Hegel exerceu uma influência decisiva tanto sobre a maneira de pensar de uma época, como também nas atitudes sociais e políticas. Influência que teria favorecido o distanciamento da pessoa humana concreta e da sociedade humana concreta em favor de uma experiência racionalizada do mundo, de processos dialéticos e formações objetivas. Criticando esta perspectiva racionalizada da experiência humana e do mundo, ele nos fala:

se o homem é o lugar e o meio onde a razão do mundo se conhece a si mesma, então não há limite algum para o que o homem pode saber. De acordo com a ideia, ele realiza tudo, tudo o que há na razão (p. 48).

Buber, em toda sua antropologia filosófica, contrapõe-se a esta perspectiva de segurança na experiência humana, e afirma que "a grandeza do homem surge de sua miséria", da "da atitude da pessoa que se encontra, sem morada, na intempérie do infinito" (Buber, 1942/1963, p. 35). Sobre o homem, Buber (1942/1963) entende que,

(...) este se encontra no mundo como um estrangeiro e um solitário. Quando se dissipa uma imagem de mundo, prontamente surge uma nova pergunta por parte deste homem que se sente inseguro, sem-teto, que se questiona sobre si mesmo (...) Uma vez que se tenha levado a sério o conceito de infinito, não é possível transformar o mundo em uma mansão para o homem (p. 36-37).

Podemos entender que, no que diz respeito ao mundo humano, delimitado pelo problema do homem, não existe nenhuma segurança sobre o futuro, sobre o desconhecido. A partir destas concepções e entendendo o processo educacional como uma experiência do mundo humano, caminhar pela Vereda Estreita nos sinaliza que não temos nenhuma garantia; há suporte, mas nenhum 
substituto para o envolvimento na experiência imediata. Lança-se assim o desafio: como utilizar a segurança das teorias e, ainda assim, não utilizá-las como uma defesa contra o desconhecido?

Outra reflexão que intencionamos estabelecer tem relação com as formas como Buber entende que se dá o conhecimento do homem. Devido à especificidade do processo educacional ao qual nos propomos, o de facilitar a formação de futuros terapeutas, entendemos que o conhecimento de que tratamos não se dá simplesmente por uma via cognitiva ou racional, mas trata-se de um conhecimento sobre o humano, conhecimento por parte do aluno de sua condição humana e da forma como ele percebe e se relaciona com os outros humanos. Neste sentido, Buber (1982/2009) nos fala de três maneiras pelas quais podemos perceber um homem que vive diante dos nossos olhos.

Uma destas formas se dá pela observação, quando se está:

(...) inteiramente concentrado em gravar na sua mente o homem que observa, em ‘anotá-lo'. Ele o perscruta e o desenha. E na verdade ele se empenha em desenhar tantos 'traços' quanto possível. Ele os vigia para que nenhum lhe escape (Buber, 1982/2009, p. 41).

Para Buber (1982/2009), outra forma se dá a partir da contemplação, quando não se está absolutamente concentrado, e é possível para o contemplador se colocar numa atitude que lhe permita ver o objeto livremente e esperar despreocupado aquilo que a ele se apresentará. Destaca que a atitude do contemplador só de início pode ser governada pela intenção, sendo que logo em seguida tudo que se segue é involuntário.

Apesar das atitudes de observação e de contemplação se caracterizarem por uma diferença significativa, Buber nos esclarece que o observador e o contemplador estão na mesma posição, justamente o desejo de perceber o homem, tomando este homem como objeto, que assim não lhes exige "nenhuma ação e nem lhes impõe destino algum; pelo contrário, tudo se passa nos campos distantes da estesia" (Buber, 1982/2009, p. 42).

Para Buber (1982/2009), existe uma percepção que é de uma espécie decididamente diferente, a qual chama de tomada de conhecimento íntimo, na qual em um dado momento receptivo de nossa vida pessoal, encontra-nos um homem em que há alguma coisa, que não conseguimos captar de uma forma objetiva, que nos 'diz algo', não significando que isto que nos foi dito fale como este homem é ou o que se passa nele, não sendo possível retratar nem descrever o homem no qual, pelo qual, algo nos foi dito, nada podemos contar sobre ele; se tentássemos fazê-lo, já seria o fim do dizer. Buber (1982/2009) ressalta que este homem não é nosso objeto, e na verdade, "o que importa agora é unicamente que eu me encarregue deste responder. Mas em cada instância aconteceu-me uma palavra que exige uma resposta" (p. 43).
Diante da exigência desta forma de tomada de conhecimento, que se mostra na necessidade de abertura para entrar em contato com a palavra que me é dirigida e da exigência de uma resposta, nos questionamos sobre a forma de podermos facilitar em nossos alunos a consciência destes três modos de conhecer, e facilitar com que nas relações com os outros em psicoterapia, seja possível uma atitude que lhes permita também uma tomada de conhecimento íntimo.

\section{A Alteridade nas Abordagens Psicológicas e na Aprendizagem das Mesmas}

Neste momento, recorremos ao trabalho de Freire (2002), onde o autor nos provoca ao questionamento sobre de que forma as abordagens psicológicas possibilitam o encontro do sujeito com a alteridade do outro e de si, com o desconhecido, o diferente, o desafiante; usando as teorias como dispositivos de "descentramento", possibilitando a dissolução das ilusões de unidade e identidade do sujeito moderno, reconhecendo a fragmentação e a multiplicidade do indivíduo. A partir destas provocações, propomo-nos a refletir sobre a necessidade de estabelecermos algumas proposições para o ensino destas psicologias, que para Freire devem possibilitar o encontro do sujeito com a alteridade do outro e de si. Parece-nos que as formas tradicionais de ensino e aprendizagem não dão conta de facilitar nos alunos a construção e a prática destas psicologias, às quais estamos sendo convocados.

Na direção das ideias de Freire (2002), Cardella (2002) no livro A construção do psicoterapeuta refere-se ao "trabalho do psicoterapeuta como confronto com a alteridade” (p. 87). A autora compreende como condição para o trabalho do psicólogo uma atitude de abertura para que a alteridade do outro ressoe em sua própria alteridade. Seria, assim, "no confronto com as alteridades do outro e de nós mesmos que este trabalho se realiza" (Cardella, 2002, p. 89).

Na tentativa de compreender e construir uma proposta de ensino que possibilite ao professor de psicologia e psicoterapia o aprendizado do aluno nesta abertura à alteridade, Cardella (2002) apoiando-se na filosofia mestiça de Michel Serres, entende o processo de aprendizagem como exposição e estranhamento. Nesta perspectiva, o processo de aprendizagem "se dá quando ocorre o 'estranhamento', a experiência de olhar de diversos ângulos ou perspectivas, de sair do lugar conhecido e familiar, de partir para o desconhecido, de desbravar" (Cardella, 2002, p. 92).

A mesma autora (2002) afirma ainda que se faz necessário que o processo de aprendizagem possibilite ao aprendiz passar pela experiência de abandono das referências, no qual se experimenta a exposição, a solidão, a errância, sendo função do educador facilitar o processo pelo qual o aluno possa viver o risco de conhecer, deslocando-o de sua estabilidade, ou seja, provocá-lo e 
facilitar sua exposição ao outro, provocando estranhamentos, o que possibilitaria que todos os sentidos possam ser vertidos.

Educar é, portanto, levar o aprendiz a compreender que é outro para si mesmo e, assim, reconhecer a existência do diferente em si e no outro. Isso possibilita um deslocamento, e a experiência da complexidade que possibilita o aprender. $\mathrm{O}$ aprendiz deve experimentar o conhecido e o enigmático, o esperado e a surpresa, o estranho e o familiar (Cardella, 2002, p. 93).

A partir desta perspectiva de Educação, Cardella (2002) afirma que o professor de psicoterapeutas deve promover a experiência de perda de referências, de errância, de suspensão, para que o aluno possa se deparar com o outro em si mesmo. A autora destaca ainda:

Na formação de psicoterapeutas é importante que haja oportunidade para que o aluno seja mobilizado, perturbado, sob pena de deixar a universidade sem aprender, num nível básico, a fazer uso de sua própria experiência, o instrumento terapêutico por excelência, e colocá-la a serviço do outro (p. 94).

Cardella (2002) sintetiza que a tarefa da formação de psicoterapeutas seria a de contribuir para que o aluno desenvolva alguma familiaridade e, talvez, muita estranheza, perante si mesmo: suas crenças, seus valores, seus afetos, suas emoções, suas concepções, seus desejos, suas necessidades, seus pontos cegos e suas dificuldades.

A partir destas colocações acerca do familiar e da alteridade, recorremos ao pensamento de Emmanuel Lévinas. Propomo-nos, assim, o diálogo com a filosofia da alteridade de Lévinas, especificamente no que diz respeito ao conceito de ensino que se dá pela epifania do rosto.

Destacamos que o pensamento de Lévinas parte de uma crítica à filosofia tradicional, em especial a ontologia, que em seu entendimento estabelece o primado do Mesmo, usurpando de suas teorizações o lugar do Outro, para Lévinas anterior a questão do Eu. Assim, Lévinas constrói seu pensamento ético-filosófico rompendo com as tradições filosóficas ocidentais, que se caracterizam pelo pensamento totalizador e pela primazia do Mesmo.

Com relação à primazia do Mesmo, para Lévinas (1980/1988) a Teoria, a Razão, e a Representação - conceitos tradicionalmente privilegiados nos processos educacionais - se traduzem como uma redução do Outro ao Mesmo, buscando assegurar a "inteligência - logos do ser - ou seja, uma maneira tal de abordar o ser conhecido que a sua alteridade em relação ao ser cognoscente se desvanece" (p. 30). Lévinas (1980/1988) estabelece uma crítica ao método socrático - a maiêutica - e afirma que o primado do Mesmo foi a lição de Sócrates: "nada receber de Outrem a não ser o que já está em mim, como se, desde toda a eternidade, eu já possuísse o que me vem de fora” (p. 31). Para Lévinas a perspectiva maiêutica, em seu sentido último, tem a ver com a permanência no Mesmo. Nestes termos, "conhecer equivale a captar o ser a partir de nada ou a reduzi-lo a nada, arrebatar-lhe a sua alteridade" (Lévinas, 1980/1988, p. 31).

Neste momento, aproximamos a concepção de Buber de tomada de conhecimento íntimo, que se dá pela condição de abertura para entrar em contato com a palavra que me é dirigida e da exigência de uma resposta, com a perspectiva levinasiana de Discurso, que se dá pela condição de abertura e resposta ao outro, logo ética. Permitimo-nos utilizar uma extensa citação de Lévinas (1980/1988) que nos esclarece as questões aqui discutidas:

O modo como o Outro se apresenta, ultrapassando a ideia do Outro em mim, chamamo-lo, de facto, rosto. Esta maneira não em figurar como tema sob meu olhar, em expor-se como um conjunto de qualidades que formam uma imagem. O rosto de Outrem destrói em cada instante e ultrapassa a imagem plástica que ele deixa, a ideia à minha medida e à medida do seu ideatum - a ideia adequada [...] Exprime-se. O rosto, contra a ontologia contemporânea, traz uma noção de verdade que não é o desvendar de um Neutro impessoal, mas uma expressão [...] Abordar Outrem no discurso é acolher a sua expressão onde ele ultrapassa em cada instante a ideia que dele tiraria um pensamento. É, pois, receber de Outrem para além da capacidade do $\mathrm{Eu}$; o que significa exatamente: ter a ideia do infinito. Mas isso significa também ser ensinado. A relação com Outrem ou o Discurso é uma relação não-alérgica, uma relação ética, mas o discurso acolhido é um ensinamento. $\mathrm{O}$ ensinamento não se reduz, porém, à maiêutica. Vem do exterior e traz-me mais do que eu contenho. Na sua transitividade não-violenta, produz-se a própria epifania do rosto (p. 37-38).

Dentro desta perspectiva ética de ensinamento, como acolhimento ao discurso, o saber significa “(...) uma relação tal com o ser que o ser cognoscente deixa o ser conhecido manifestar-se, respeitando a sua alteridade e sem o marcar, seja no que for, pela relação de conhecimento" (Lévinas, 1980/1988, p. 29). Sabedoria ensinada pelo rosto do outro homem, na medida em que abrimos mão dos saberes totalizantes que se dão pela primazia do Mesmo. Ensinamento ético a partir do qual “(...) o Mesmo só pode juntar-se ao Outro nas vicissitudes e nos riscos da procura da verdade, em vez de descansar em si em toda a segurança” (Lévinas, 1980/1988, p. 48).

Por fim, para Lévinas (1980/1988) "afirmar a verdade como modalidade da relação entre o Mesmo e o Outro não equivale a opor-se ao intelectualismo, mas a assegurar a sua aspiração fundamental, o respeito do ser que ilumina o intelecto" (p. 51), mas destaca que "a experiência do Outro a partir de um Eu separado continua a ser uma fonte de sentido para a compreensão das totalidades, tal 
como a percepção concreta continua a ser determinante para a significação dos universos científicos” (p. 45). Se tomarmos a afirmação de Lévinas no âmbito dos discursos e práticas psicológicas, ressalta-se a necessidade de um processo de aprendizagem que possibilite o encontro e o acolhimento do Outro, da diferença, do estranho, em oposição aos discursos teóricos e práticas de ensino totalizantes, que se fundamentam em verdades absolutas e redutoras de toda alteridade ao primado do Mesmo, do Saber, da Teoria, haja vista que são muitas as escolas e abordagens psicológicas que se propõem em seus projetos epistemológicos uma aproximação com o quadro das ciências naturais, gozando assim, de um status de verdade.

\section{Versando Sentidos sobre a Aprendizagem em Gestalt-Terapia}

Retomando neste momento nosso questionamento inicial - Como se dá o processo de facilitação da aprendizagem em Gestalt-terapia no ambiente acadêmico? - e na tentativa de respondê-lo não mais apenas a partir dos referenciais teóricos da Gestalt-terapia, mas também a partir das experiências vividas no Curso de Capacitação na Abordagem Gestáltica, propomos a utilização do recurso metodológico da Versão de Sentido proposta por Mauro Martins Amattuzi, e que vem sendo utilizada em pesquisas fenomenológicas e nos processos de supervisão clínica na formação de psicoterapeutas.

Amatuzzi (2002) entende por Versão de Sentido (VS) um relato livre, escrito ou falado, que não tem a pretensão de ser um registro objetivo do que aconteceu, mas sim de ser uma reação viva a isso, como uma palavra primeira. Consiste numa fala expressiva da experiência imediata de seu autor, face a um encontro recém-terminado.

Entendemos a pertinência desta proposta metodológica aos objetivos deste estudo exploratório, por entender que o mesmo nos possibilita compreender os sentidos das experiências vividas no processo de aprendizagem da Gestalt-terapia, bem como de ilustrar nossa proposta de ensino/aprendizagem ao longo da experiência aqui retratada. Propomos assim, apresentar e discutir alguns recortes das Versões de Sentido realizadas por uma aluna do referido curso, que foram realizadas ao término de quatro encontros, com duração média de três horas cada um, e que se deram por volta do meio do curso.

Tomamos como proposta didática norteadora de nosso trabalho docente uma metodologia teórico-vivencial, que privilegiasse a leitura e discussão de textos filosóficos e teóricos que fundamentam epistemologicamente a Gestalt-terapia. A partir da leitura dos textos era solicitado aos alunos que entrassem em contato com a forma como aqueles os tocavam. Tal proposta pode ser ilustrada a partir da fala da aluna: "O João Vitor sempre faz perguntas pra saber qual a relação que estabelecemos entre o que estudamos e o que fazemos da nossa vida, e a maioria de- las são bem inquietantes”. Tal fala nos sinaliza a riqueza desta proposta de explicitar o diálogo entre o aluno e o texto no processo de aprendizagem, promovendo também ao longo das discussões questionamentos sobre a forma como as temáticas trazidas pelo texto os afetaram e que respostas são formuladas a partir dos questionamentos, interpelações, exigências que as obras nos trazem.

Entendemos que ao tomarmos a discussão a partir do campo existencial dos alunos, diminuindo assim o distanciamento entre a teoria e suas experiências concretas, possibilitamos que os mesmos entrem em contato com os fundamentos da Abordagem Gestáltica a partir de suas referências existenciais, o que possibilita também que estas possam ser confrontadas com as concepções éticas e estéticas da Abordagem Gestáltica. Neste sentido a aluna nos fala:

Achei a dinâmica do dia bem interessante, pois refletimos e conversamos sobre categorias como desespero, sofrimento, solidão, impotência, segurança, liberdade... Mais uma vez o facilitador solicitou que o grupo se colocasse diante dessas categorias de forma pessoal e compartilhassem o modo como somos afetados e o significado daquilo na vida de cada um, de forma a perceber quais crenças nos guiam e como isso pode se refletir na nossa atitude como psicoterapeuta.

Entendemos que o diálogo entre a teoria e as experiências concretas dos alunos possibilita-os darem-se conta de suas crenças, seus valores, seus afetos, suas emoções, suas necessidades, seus pontos cegos e suas dificuldades, processo de conscientização tão importante para a formação do psicoterapeuta. Permite ainda aos alunos darem-se conta do que muitas vezes é vivenciado de maneira conflitiva e angustiante, o que pode ser percebido a partir da seguinte fala: "Em vários momentos me questionei sobre como eu serei psicoterapeuta se eu tenho tanta dificuldade em acolher algumas falas de algumas pessoas". Entendemos que este processo de conscientização de si e do outro, possibilita aos alunos entrarem em contato com a diferença em si e no outro, consciência da alteridade. Assim o processo do grupo, mesmo em se tratando de um grupo didático-vivencial, como em nossa experiência no curso de capacitação, nos possibilita a experiência de olhar de diversos ângulos ou perspectivas, de sair do lugar conhecido e familiar. A partir da experiência imediata grupal se dá a facilitação de uma vivência compreensiva sobre a experiência de si e do outro, o que reforça a herança fenomenológica da Abordagem Gestáltica.

O desafio desta vivência grupal compreensiva no contexto do curso nos sinaliza a importância do processo de construção de um clima de acolhimento das experiências e das alteridades percebidas no grupo, o que ultrapassa a perspectiva de estabelecimento de um clima de confiança mútua, franqueza e autenticidade na relação inter-humana professor-aluno, e instaura o desafio des- 
te clima nas relações grupais como um todo, que passa a ser entendido e vivido como um dos principais aspectos na mediação do processo de aprendizagem em Gestaltterapia. "Ainda é difícil para o grupo se expor e realmente se implicar nas vivências propostas, mas acho que nesse encontro caminhamos para uma maior cumplicidade e intimidade”.

Interessante percebermos o que nos é revelado pela aluna quando fala do grupo, que apesar de não se configurar como uma proposta de grupo terapêutico, possui intencionalmente elementos deste ${ }^{1}$. Sobre o grupo nos é dito:

É engraçado que pra mim o curso às vezes parece um grupo terapêutico, em que eu vou ampliando minha consciência e minha percepção sobre o fazer do psicoterapeuta. Acho que isso também se dá principalmente devido as pontuação e interrogações que o João Victor faz, que são geralmente bem pessoais e profundas. Como o grupo não é terapêutico e ainda não há tanta cumplicidade, algumas questões não podem ser aprofundadas e por isso ficam em aberto e continuam ressoando depois.

O trabalho com o grupo e o compartilhar de experiências em nosso entendimento possibilitam o questionamento e o possível abandono das teorias totalizantes, na medida em que é permitido aos alunos expressarem as mais diversas experiências sobre os temas suscitados pelos textos e discussões, afirmando os diversos sentidos possíveis para a experiência humana. A forma como os alunos são afetados e respondem a cada experiência concreta em sala de aula atestam a impossibilidade de esgotar os sentidos da experiência humana, apontando assim para além do Mesmo.

Compreendemos assim, que o espaço didático-vivencial do grupo nos permite acessar aquilo que Buber denomina de tomada de conhecimento íntimo, ou a perspectiva de ensino proposta por Lévinas, na medida em que possibilita a partir de uma condição de abertura ao outro a experiência de ser provocado, afetação que exige uma resposta. Afetação esta que nos damos conta pela inquietação, desconforto e sensação de sair mexido expressa pelos alunos, como descrita na fala anterior da aluna.

Na intenção de promover um espaço mais fértil possível para esta condição de afetação e resposta, propomo-nos também a utilização de outros recursos tais como contos, poesias e filmes que buscam permitir no processo educacional o conhecimento não apenas pela via da racionalidade, mas também pela sensibilidade. Em um dado encontro, propomos o filme O Escafandro e a Borboleta dirigido por Julian Schnalbe, novamente solicitando aos alunos que buscassem darem-se conta de como eram afetados pelo filme. Neste sentido, a aluna nos fala

\footnotetext{
Enquanto facilitadores têm-se consciência dos limites éticos e das possibilidades terapêuticas do espaço proposto.
}

[...] fiquei observando como cada cena me afetava e quais partes me chamavam mais atenção [...] Fiquei emocionada com a cena em que o pai liga pra ele, e não sei explicar porque, mas acho que ali mostra mais uma vez a sensação de impotência dos dois diante da vida.

A fala da aluna nos remete ao conceito de Inclusão, que trabalhamos anteriormente, e que se faz presente como um dos conceitos básicos da clínica gestáltica, entendido como a condição de entrar em contato, tanto quanto possível, com a experiência vivida pelo outro.

Uma última fala da aluna nos parece bastante interessante para evidenciarmos nosso esforço para a superação da histórica dicotomização teoria e vivência nos processos de formação dos gestalt-terapeutas:

Fiquei muito feliz por conseguir enxergar distúrbios de contato como a confluência e a retroflexão em casos reais que eu conheço, o que me transmitiu momentaneamente uma sensação de segurança em relação a minha atuação na clínica no próximo semestre [...] Já aconteceu, mais de uma vez, de eu 'fechar algumas gestalten' teóricas no grupo [...].

Propomo-nos assim, uma perspectiva integrativa destes aspectos do processo de aprendizagem, da experiência humana, o que intencionamos evidenciar em nossa proposta de diálogo dos alunos com os textos a partir de suas experiências concretas. Uma proposta didática que enfatiza os aspectos experienciais dos afetos e emoções, de autoconhecimento e das relações interpessoais da situação de aprendizagem sem, no entanto, desvalorizar a transmissão de conhecimentos no ensino.

\section{Considerações Finais}

Intencionamos, a partir deste estudo exploratório, compreender como se dá o processo de facilitação da aprendizagem em Gestalt-terapia no ambiente acadêmico, e, neste intento, caminhamos pelos referenciais teóricos da abordagem, bem como pelas experiências vividas no Curso de Capacitação na Abordagem Gestáltica, a partir das Versões de Sentido.

Ao entendermos a Gestalt-terapia como construção sócio-histórica, temos consciência de seu próprio contínuo processo de (re)construção, da mesma forma, das respostas que a abordagem dá a sociedade contemporânea, afirmando a importância do sentido ético dos discursos e práticas psicológicas. Compreendemos também que na tentativa de melhor se organizar em seus fundamentos epistemológicos e teóricos, a Gestalt-terapia se apresenta hoje de maneira cada vez mais presente no âmbito acadêmico, o que afirma a necessidade de pensarmos como se dá o processo de aprendizagem da Gestalt-terapia nestes espaços. 
Destaca-se que na tentativa de superação de antigas dicotomias presentes nos primeiros momentos do desenvolvimento da Abordagem Gestáltica, propomos uma prática docente compromissada e pautada no rigor teórico-epistemológico, no entanto, sem esquecer o aspecto vivencial, tão enfatizado pelas abordagens fenomenológico-existenciais.

Ao entendermos a Gestalt-terapia como uma abordagem que propõe uma perspectiva compreensiva do outro, em que se toma como fundamento de sua prática clínica a abertura à consciência, o diálogo e o confronto com a alteridade, defendemos uma prática docente que possibilite aos alunos a consciência da alteridade em si e do outro. Prática docente que possibilite afetação, em que se experiencie momentaneamente o abandono das referências, das seguranças do conhecido, e que proponha um conhecimento a partir desta afetação provocada pela exposição ao outro do professor, dos livros e das experiências vividas a partir da experiência concreta em sala de aula. Experiência que promova estranhamento e uma certa familiaridade, mas que tenha como intenção provocar respostas por parte dos alunos e do professor, respostas às exigências de cada situação vivida, cada texto, cada face que se apresente e que exija esta implicação responsiva.

Entendemos a necessidade de investimento em estudos mais profundos que tomem esta temática, haja vista que ainda nos parecem reduzidos os trabalhos que se propõem a versar sobre o processo de ensino/aprendizagem no âmbito acadêmico. Esperamos que a partir do contato dos leitores com a presente obra novas inquietações possam ser vivenciadas; questionamentos, divergências, mobilização que sinalizem afetação e que possibilitem o responder. Que os leitores, alunos e mestres, se conscientizem desta palavra que lhes é dirigida como texto, e que nos digam: "e o que me importa agora é unicamente que eu me encarregue deste responder. Mas em cada instância aconteceu-me uma palavra que exige uma resposta" (Buber, 1982/2009, p. 43).

\section{Referências}

Amatuzzi, M. M. (2010). Por uma psicologia humana. Campinas: Editora Alínea.

Buber, M. (1963). ¿Qué es el hombre?. México, DF: Fondo de Cultura Económica (Original publicado em 1942).

Buber, M. (2009). Do diálogo e do dialógico. São Paulo: Debates (Original publicado em 1982).
Burow, O. A., \& Scherpp, K. (1985). Gestaltpedagogia: um caminho para a escola e a educação. São Paulo: Summus.

Cardella, B. H. P. (2002). A construção do psicoterapeuta: uma abordagem gestáltica. São Paulo: Summus.

Figueiredo, L. C. M. (2009). Revisitando as psicologias: da epistemologia à ética das práticas e discursos psicológicos. Petrópolis: Vozes.

Freire, J. C. (2002). O lugar do Outro na modernidade tardia. São Paulo: Annablume.

Friedman, M. S. (2002). Martin Buber: the life of dialogue. New York, NY: Routledge.

Karwowski, S. L. (2005). Prefácio. Em A. F. Holanda \& N. J. de Faria (Orgs.), Gestalt-terapia e contemporaneidade: contribuições para uma construção epistemológica da teoria e da prática gestáltica, pp. 09-12. Campinas: Livro Pleno.

Holanda, A. F. (2005). Elementos de Epistemologia da Gestaltterapia. Em A. F. Holanda \& N. J. de Faria (Orgs.), Gestaltterapia e contemporaneidade: contribuições para uma construção epistemológica da teoria e da prática gestáltica (pp. 23-55). Campinas: Livro Pleno.

Hycner, R. (1997). Relação e cura em Gestalt-terapia. São Paulo: Summus.

Lévinas, E. (1988). Totalidade e Infinito. Lisboa: Edições 70 (Original publicado em 1980).

Moreira, V. (2007). De Carl Rogers a Merleau-Ponty: a pessoa mundana em psicoterapia. São Paulo: Annablume.

João Vitor Moreira Maia - Mestrando em Psicologia pelo Programa de Pós-Graduação em Psicologia da Universidade Federal do Ceará (Bolsista Capes/Propag); Gestalt-terapeuta e Coordenador Pedagógico do Instituto Gestalt do Ceará. Endereço Institucional: Instituto Gestalt do Ceará, Rua João Regino, 474 (Parque Manibura). CEP 60821-780, Fortaleza/CE, Brasil.E-mail: jv_psi@yahoo.com.br.

José Célio Freire - Professor Associado do Departamento de Psicologia e do Mestrado em Psicologia da Universidade Federal do Ceará. Endereço Institucional: Departamento de Psicologia. Av. da Universidade, 2762 (Campus do Benfica), CEP 60020-180, Fortaleza/CE, Brasil. E-mail: jcfreire@ufc.br.

Mariana Alves de Oliveira - Graduanda em Psicologia pela Universidade Federal do Ceará e Aluna do Curso de Capacitação na Abordagem Gestáltica.E-mail: marianadeo@hotmail.com.

Recebido em 10.05.2012

Primeira Decisão Editorial em 25.09.2012

Aceito em 12.12.2012 